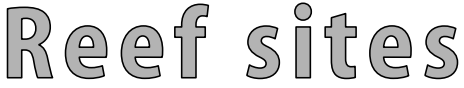

\section{First record of a christmas tree worm in a mushroom coral (Loyalty Islands, Southwest Pacific)}
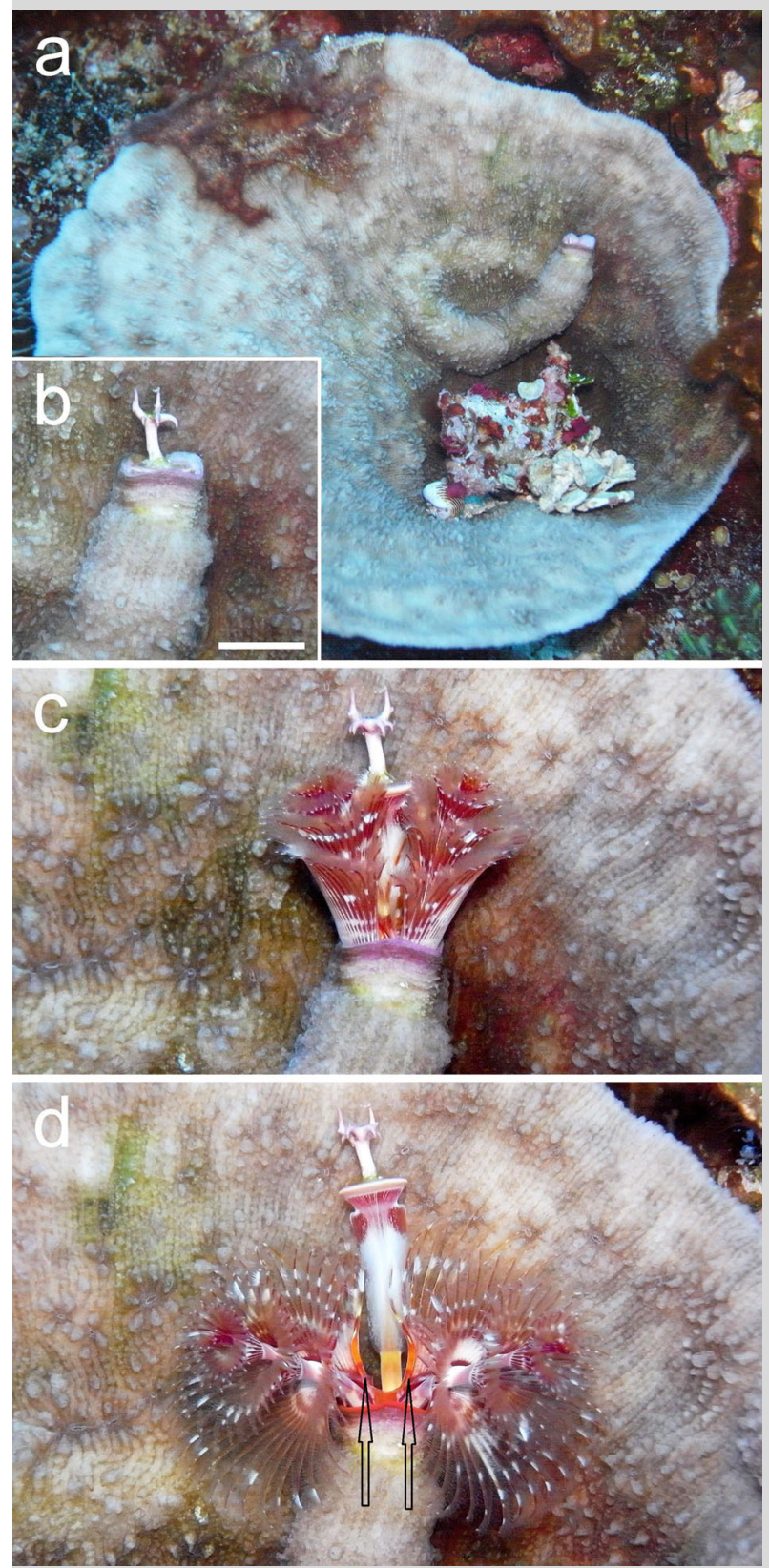

Fig. 1 Spirobranchus richardsmithi embedded in a Podabacia motuporensis coral. a Position of the tube; worm retracted. b Antler-shaped opercular spines protruding above the tube (scale bar $0.5 \mathrm{~cm}$ ). c Twin spirals unfolding. d Worm completely expanded, peduncle with operculum sticking upward, and orange
Owing to their striking shape, colours, and retraction behaviour, christmas tree worms of the genus Spirobranchus (Polychaeta: Serpulidae) are well-known associates of reef corals, especially in shallow water. Host taxa are seldom mentioned in taxonomic studies on serpulids, with the exception of Porites (Stella et al. 2011). Although mushroom corals (Fungiidae) have been the subject of a review study on coral-associated fauna, they are unknown as a hosts for serpulids (Hoeksema et al. 2012).

During a biodiversity survey at Lifou Island in the Loyalty Islands $\left(20^{\circ} 51.328^{\prime} \mathrm{S}, 166^{\circ} 23.791^{\prime} \mathrm{E}\right)$ on 18 February 2014 , an attached mushroom coral, Podabacia motuporensis Veron, 1990, with a serpulid tube was found on the reef slope at $25 \mathrm{~m}$ depth (Fig. 1a). A series of photographs was made to document the process of the worm's protrusion from its tube starting by the operculum (Fig. 1b) and succeeded by the unfolding twin spiral branchiae at both sides of the peduncle (Figs. 1c, d). Based on the arrangement of the antlerlike spines of the operculum and the mauve tube colouration, the worm was identified as Spirobranchus richardsmithi Pillai, 1990. The animal has been deposited in the collection of Naturalis Biodiversity Center (catalogue number RMNH.VER. 19906).

Since taxonomists specialized in Serpulidae tend to study museum specimens isolated from their hosts (e.g. Pillai 2009), pictures of the living animal and information on its possible hosts were unknown so far, which also applies to many of its congeners. Obviously, more field studies are needed to clarify whether these spectacular worms show host specificity.

Acknowledgments Data were collected during the BIBELOT campaign onboard RV Alis of IRD at Nouméa. The first author is grateful to Cecile Fauvelot and Claude Payri for the invitation to join this expedition. Francesca Benzoni was dive buddy. Sampling permits were granted by the Loyalty Islands Province, New Caledonia.

\section{References}

Hoeksema BW, van der Meij SET, Fransen CHJM (2012) The mushroom coral as a habitat. J Mar Biol Assoc UK 92:647-663

Pillai TG (2009) Descriptions of new serpulid polychaetes from the Kimberleys of Australia and discussion of Australian and Indo-West Pacific species of Spirobranchus and superficially similar taxa. Rec Aust Mus 61:93-199

Stella JS, Pratchett MS, Hutchings PA, Jones GP (2011) Coral-associated invertebrates: diversity, ecology importance and vulnerability to disturbance. Oceanogr Mar Biol Annu Rev 49:43-104

B. W. Hoeksema $(\bowtie) \cdot$ H. A. ten Hove

Department of Marine Zoology, Naturalis Biodiversity Center, P.O. Box 9517, 2300 RA Leiden, The Netherlands

e-mail: bert.hoeksema@naturalis.nl

Received: 12 March 2014/ Accepted: 20 May 2014/Published online: 4 June 2014

Coral Reefs (2014) 33:717

Springer-Verlag Berlin Heidelberg 2014

DOI $10.1007 / \mathrm{s} 00338-014-1175-9$ 